\title{
Erratum
}

\section{Tandem Aza-Michael-Condensation-Aldol Cyclization Reaction: Approach to the Construction of DE Synthon of $( \pm)$-Camptothecin}

Subhash P. Chavan, * Abasaheb N. Dhawane, Uttam R. Kalkote Synlett 2008, 2781.

In the original Scheme 3 the structure of compound 15 was incorrect. The correct structure is depicted below.

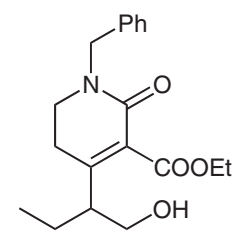

15 